\title{
Influences of forest gaps on soil physico-chemical and biological properties in an oriental beech (Fagus orientalis L.) stand of Hyrcanian forest, north of Iran
}

\author{
Alireza Amolikondori ${ }^{(1)}$, \\ Kambiz Abrari Vajari ${ }^{(1)}$, \\ Mohammad Feizian ${ }^{(1)}$, \\ Antonino Di lorio ${ }^{(2)}$
}

\begin{abstract}
Understanding the effects of silvicultural practices including single-tree selection on soil properties is essential for forest management in temperate broadleaved beech forests. Changes in physico-chemical and biological soil properties in 15 harvest-created gaps under single-tree selection and the adjacent closed canopies, with five replications for each, were studied 6 years after gap creation in an oriental beech (Fagus orientalis L.) stand of the Hyrcanian forest. Gaps were classified into three size classes: small $\left(85-130 \mathrm{~m}^{2}\right)$, medium $\left(131-175 \mathrm{~m}^{2}\right)$ and large $\left(176-300 \mathrm{~m}^{2}\right)$. Soil cores were collected at the center and at the edge of gaps, and under the adjacent closed canopy. Results indicated that gap size significantly affected soil texture and bulk density, whereas soil organic carbon (SOC), total nitrogen and $\mathrm{pH}$ showed a significant gradient from the center to the edge of gap independently form their size. SOC and total nitrogen at the center of gaps were also significantly lower than closed-canopy, in particular for the medium-gap; contrastingly, the bulk density with the highest mean value was found at the center of the large-gap. Gap size had no significant influence on soil microbial biomass. These results highlighted that similar conditions in terms of many soil properties were still present among gaps and adjacent closed-canopy stands six years after logging, though canopy openness triggered a reduction in carbon and nitrogen availability along with the related microbial activity at the center of gaps, independently from their size. Therefore, if aimed at preserving an uneven aged structure along with soil quality in temperate broadleaved deciduous forest as the oriental beech stands in the Hyrcanian region, single-tree selection practice for harvesting trees can be recommended as sustainable forest management type.
\end{abstract}

\section{Keywords: Artificial Gap, Oriental Beech, Temperate Forests, Soil Properties}

logical processes following the gap formation are essential for sustainable forest management systems. Forest gaps are different sized spaces in the canopy and are due to the damage or death of one or more trees (Yamamoto 2000). Many environmental variations take place after the formation of a gap (D'Oliveira \& Ribas 2011), among which the changes in the distribution of living and non-living resources, whose impact is crucial on both aboveground and belowground ecological pro-
(1) Faculty of Agriculture and Natural Resource, Lorestan University, Khorramabad (Iran); (2) Department of Biotechnology and Life Science, University of Insubria, 21100 Varese (Italy)

@ Kambiz Abrari Vajari (abrari.k@lu.ac.ir)

Received: Jul 30, 2019 - Accepted: Jan 25, 2020

Citation: Amolikondori A, Abrari Vajari K, Feizian M, Di lorio A (2020). Influences of forest gaps on soil physico-chemical and biological properties in an oriental beech (Fagus orientalis L.) stand of Hyrcanian forest, north of Iran. iForest 13: 124-129. - doi: 10.3832/ifor3205-013 [online 2020-04-07]

Communicated by: Giorgio Alberti cesses in forests (Liu et al. 2018). Indeed, gaps influence the forest soil which is a vital part of the ecosystem functioning (Yang et al. 2017). According to Scharenbroch \& Bockheim (2007), different elements may influence soil processes including climate, organisms, physiography, parent material, time, and human activities. For example, the soil microbial biomass plays an important role in the nutrients cycle (Yang et al. 2010), resulting an important indicator of soil fertility for the ecological research and sustainable forest management (Ravindran \& Yang 2015). The canopy gap alters the microclimatic features of the soil and, consequently, the soil microbial biomass and respiration (Bolat 2014). Knowing about the amount of soil nutrients and its relationship to gap dynamics can afford valuable insights on forest ecosystem functioning. Previous studies have shown that soil physic-chemical and biological features were affected by gaps in different forest types. In old growth northern hardwoodhemlock forests (USA), Scharenbroch \& Bockheim (2007) reported that the value of exchangeable cations in the $0-25 \mathrm{~cm}$ mineral soil depth was lower in gaps than 
in closed canopy. In European silver fir stands (Abies alba Mill) in Italy, Muscolo et al. (2007a) reported the occurrence of chemical and microbiological variations in the soil of gaps. Other studies investigating soil respiration (Saner et al. 2009, Pang et al. 2013), microclimate variables (He et al. 2012), microbial community (Schliemann \& Bockheim 2014, Lewandowski et al. 2015), microbial biomass (Arunachalam \& Arunachalam 2000, Muscolo et al. 2007b), enzyme activities (Yang et al. 2017) have also confirmed the influences of forest gaps on soil properties. The study of forest gaps dynamics is essential to understanding ecosystem function and predicting how forest ecosystems respond to disturbance and to forest management.

Oriental beech (Fagus orientalis L.) which belongs to the family Fagaceae is one of the most widespread broadleaved trees in mixed and pure stands of the Hyrcanian temperate forests. In these stands, different gap sizes have been generated by using different silvicultural systems, especially the single-tree selection harvesting method. Despite the importance of forest gaps in the development of Hyrcanian temperate forests, there is inadequate information of their effects on soil properties. This research aimed at determining the influences of forest gaps on soil features in broad-leaf, deciduous beech stand. Specific objectives of this study were: (i) to determine the effect of gap size on physicochemical and biological properties of soil; (ii) to compare soil features among different positions (center, edge of gap and closed canopy); and (iii) to evaluate the correlation between gap size and soil properties.

\section{Materials and methods}

\section{Site description}

The study was carried out in an unevenaged beech (Fagus orientalis Lipsky) forest located in the Hyrcanian region, northern Iran ( $\left.36^{\circ} 12^{\prime} \mathrm{N}, 53^{\circ} 24^{\prime} \mathrm{E}\right)$, approximately from 1000 to $1200 \mathrm{~m}$ a.s.l. This site covers an area of about 40.4 ha on a $0-30 \%$ northfacing slope. The climate is humid, with a mean annual precipitation of $858 \mathrm{~mm}$ mostly concentrated in autumn, and a mean annual temperature of $10.5^{\circ} \mathrm{C}$. The dominant soil types are pseudogleyic and gley. Oriental beech trees occupy all forest layers, from overtopped to dominant ones. To a lesser extent, other tree species including alder (Alnus subcordata C.A. Mey), hornbeam (Carpinus betulus L.) and maple (Acer velutinum Boiss.) are commonly present. The broadleaved, multi-layered and uneven-aged beech stand originated from natural regeneration. The stand was managed under the single-tree selection silvicultural system in 2011. Under the current silvicultural system, different canopy gaps have generally been created within the stand. These harvest-generated gaps were randomly extended at the site. In total, 15 artificial gaps were sampled and categorized in three size classes of five replicates each: small $\left(85-130 \mathrm{~m}^{2}\right)$, medium (131-175 $\mathrm{m}^{2}$ ) and large $\left(176-300 \mathrm{~m}^{2}\right)$. The gap area was measured using the formula for an ellipse: $A=(\pi L W) / 4$, where $L$ is the longest distance within the gap $(\mathrm{m})$, and $W$ is the largest distance perpendicular to $L(m-$ Fig. 1). These distances were measured between stems of the trees at the border. All gaps were oriented in north exposition within forest (Fig. 1).

\section{Soil sampling}

Soil samples were taken in October 2017, six years after gap creation. After removal of the litter layer, soil samples were collected by hand soil corer ( $8 \mathrm{~cm}$ diameter) from the shallower rooted soil layer up to $20 \mathrm{~cm}$ depth. The sampling protocol followed the scheme reported in Fig. 1. For each gap, 4 soil samples were collected at the cardinal points of the gap border and 4 at the adjacent closed canopy at a distance of $20 \mathrm{~m}$ from the gap (Fig. 1). The four gapedge-cores were mixed to produce one composite sample (hereafter named gapedge-core); the same was done for closed canopy cores (hereafter named close-

Fig. 1 - Sketch of location of the sampling points within gap and adjacent closed canopy. Capital letters indicate cardinal points.

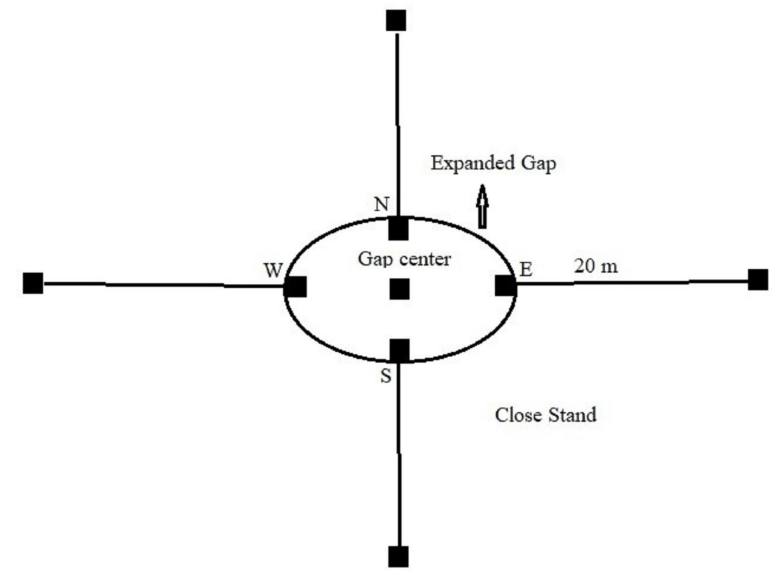

canopy-core). One more core was collected at the center of the gap (hereafter named gap-center-core), so that soil samples totaled three per gap. Each composite soil sample was air dried and sieved to 2 $\mathrm{mm}$ mesh size, and any living plant material was removed manually from the sieved soil to accomplish physico-chemical analysis. A subsample of each soil was stored at $4{ }^{\circ} \mathrm{C}$.

\section{Physico-chemical analysis of soil}

Physico-chemical properties of soil were analyzed based on Page (1992). Soil pH was determined using a $\mathrm{pH}$ meter after shaking the soil:water $(1: 1, w / v)$ suspension for 1 hour. Bulk density (BD, $\mathrm{g} \mathrm{cm}^{-3}$ ) at air-dried moisture content was calculated by clod method; soil bulk density was measured by calculating soil mass and volume using paraffin wax using the following steps. In clod method, soil bulk density is calculated through computing soil mass and volume by using paraffin wax and going through these steps: at first, the weight of a clod is determined and its volume is measured by covering it in paraffin wax heated up to 65$70{ }^{\circ} \mathrm{C}$ and the clod is plunged in the wax bath for roughly $24 \mathrm{~h}$. The waxed clod is first weighed in the air and then weighed in the given volume of water where the water temperature is measured and the mass is checked yet again (Al-Shammary et al. 2018). Soil texture (sand, silt and clay) was determined using the Bouyoucos hydrometer method. In the case of hydrometer method, the methodology described in the work of Bouyoucos (1962) and Papuga et al. (2018) was applied. Soil moisture (\%) was obtained by drying soil samples at 105 ${ }^{\circ} \mathrm{C}$ for $24 \mathrm{~h}$. Water content was obtained by dividing the difference between wet and dry masses by the mass of the dry sample. Soil organic carbon (SOC, \%) was assessed using Walkley \& Black (1934) method which involves oxidation of organic matter by $\mathrm{K}_{2} \mathrm{Cr}_{2} \mathrm{O}_{7}$ with $\mathrm{H}_{2} \mathrm{SO}_{4}$ heat of dilution and then titrated with ferrous ammonium sulfate. Total $\mathrm{N}$ content was determined by the Kjeldahl method (Brookes et al. 1982). Phosphorus $\left(\mathrm{P}, \mathrm{mg} \mathrm{kg}^{-1}\right)$ was obtained by the method of Olsen et al. (1954). This method used a 2.5 -g sample shaken with

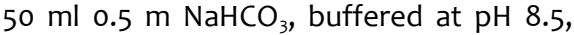
for 30 minutes and filtering extracts through Whatman no. 42 filter paper. $P$ concentration was determined by inductively coupled plasma atomic emission spectroscopy (ICP-AES); blank and standards were prepared in Olsen $\mathrm{P}$ extracting solution (Chaouqi et al. 2017).

\section{Soil microbial biomass $C, N$ and $P$}

Soil microbial biomass carbon (MBC), nitrogen (MBN) and phosphorous (MBP) were obtained using the chloroform fumigation-extraction method based on Brookes et al. $(1982,1985)$ using $\mathrm{K}_{2} \mathrm{SO}_{4}(0.5 \mathrm{M})$ and $\mathrm{NaHCO}_{3}(0.5 \mathrm{M})$ as extracting solution in $M B C, M B N$ and $M B P$, respectively. Briefly, weighed portions of moist soil were put into a desiccator containing wet filter pa- 
per and alcohol-free liquid $\mathrm{CHCl}_{3}$. The desiccator was evacuated on a water pump until the $\mathrm{CHCl}_{3}$ had boiled vigorously for $5 \mathrm{~min}$. The desiccator containing $\mathrm{CHCl}_{3}$ was kept at $25{ }^{\circ} \mathrm{C}$ until the fumigated soil was required for chemical analysis. Control, nonfumigated soil was treated similarly, except that the desiccator contained no $\mathrm{CHCl}_{3}$ and was not evacuated.

Microbial biomass $C$ was measured by extracting the fumigated soil immediately following $\mathrm{CHCl}_{3}$ removal by shaking for $30 \mathrm{~min}$ with $0.5 \mathrm{M} \mathrm{K}_{2} \mathrm{SO}_{4}$ at a solution:soil ratio of 4:1. After filtration through a Whatman no. 42 filter paper, the filtrate was analyzed for organic $\mathrm{C}$ using dichromate digestion. Microbial biomass $C$ was calculated as follows: $M B C=E C \cdot(2.64)$, where $E c$ is the different between organic $C$ extracted by 0.5 $\mathrm{M} \mathrm{K}_{2} \mathrm{SO}_{4}$ from fumigate and non-fumigated soil (Vance et al. 1987) and also MBN was calculated from the difference between the amount of inorganic $\mathrm{N}$ extracted by 0.5 $\mathrm{M} \mathrm{K}_{2} \mathrm{SO}_{4}$ from fresh soil fumigated with $\mathrm{CHCl}_{3}$ and the amount extracted from unfumigated soil by dividing by 0.54 (Alef \& Nannipieri 1995, Joergensen \& Mueller 1996). MBP was calculated from the difference between the amount of inorganic $P$ extracted by $0.5 \mathrm{M} \mathrm{NaHCO}_{3}$, (pH 8.5) from fresh soil fumigated with $\mathrm{CHCl}_{3}$ and the amount extracted from unfumigated soil by dividing by 0.4 (Brookes et al. 1982).

\section{Soil respiration}

The $\mathrm{CO}_{2}$ emission from each soil sample was estimated after incubation for 3 days at $25{ }^{\circ} \mathrm{C}$ ( $55 \%$ water content) in a closed system. $\mathrm{CO}_{2}$ was trapped in a $\mathrm{NaOH}$ solution, which was then titrated with $\mathrm{HCl}$ (Alef \& Nannipieri 1995).

\section{Statistical analyses}

To compare the three gap-size classes, 5 artificial gaps (replicates) per size class were established. Two-way ANOVA was performed to evaluate the effects of gap size and within-gap core position. Data were transformed where necessary to meet assumptions. One-way ANOVA fol-
Tab. 1 - $F$ and $P$ values of ANOVA (GLM) for the effects of gap-size and within gap core position for gaps cores only on soil physico-chemical variables. (SOC): Soil organic carbon; (Total N): Total Nitrogen; (P): Phosphorus; (BD): Bulk Density.

\begin{tabular}{|c|c|c|c|c|}
\hline \multirow[t]{2}{*}{ Variable } & \multirow[t]{2}{*}{ Stats } & Gap size & $\begin{array}{l}\text { Within Gap } \\
\text { Position }\end{array}$ & $\begin{array}{c}\text { Gap size } \times \\
\text { W-G Position }\end{array}$ \\
\hline & & $(d f=2)$ & $(d f=1)$ & $(d f=2)$ \\
\hline \multirow[t]{2}{*}{ SOC (\%) } & $\mathrm{F}$ & 1.589 & 5.1 & 0.174 \\
\hline & $P$ & 0.227 & 0.034 & 0.841 \\
\hline \multirow[t]{2}{*}{ Total N (\%) } & $\mathrm{F}$ & 1.822 & 5.451 & 0.268 \\
\hline & $P$ & 0.183 & 0.028 & 0.767 \\
\hline \multirow[t]{2}{*}{$P\left(\mathrm{mg} \mathrm{kg}^{-1}\right)$} & $\mathrm{F}$ & 1.902 & 0.157 & 0.441 \\
\hline & $P$ & 0.171 & 0.695 & 0.648 \\
\hline \multirow[t]{2}{*}{ Clay (\%) } & $\mathrm{F}$ & 5.41 & 4.519 & 0.249 \\
\hline & $P$ & 0.011 & 0.044 & 0.782 \\
\hline \multirow[t]{2}{*}{ Silt (\%) } & $\mathrm{F}$ & 2.741 & 0.371 & 0.177 \\
\hline & $P$ & 0.085 & 0.548 & 0.839 \\
\hline \multirow[t]{2}{*}{ Sand (\%) } & $\mathrm{F}$ & 4.804 & 5.98 & 0.724 \\
\hline & $P$ & 0.018 & 0.022 & 0.495 \\
\hline \multirow[t]{2}{*}{$\mathrm{pH}$} & $\mathrm{F}$ & 0.591 & 4.275 & 0.64 \\
\hline & $P$ & 0.562 & 0.048 & 0.536 \\
\hline \multirow[t]{2}{*}{$\mathrm{BD}\left(\mathrm{g} \mathrm{m}^{-3}\right)$} & $\mathrm{F}$ & 5.934 & 2.617 & 0.686 \\
\hline & $P$ & 0.008 & 0.119 & 0.513 \\
\hline \multirow{2}{*}{$\begin{array}{l}\text { Moisture content } \\
(\%)\end{array}$} & $\mathrm{F}$ & 0.325 & 0.051 & 2.335 \\
\hline & $P$ & 0.726 & 0.823 & 0.118 \\
\hline
\end{tabular}

lowed by the least significant difference (LSD) test were performed among the three closed-canopy controls to exclude possible differences among them. To test the difference between the gaps and the closed-canopy, a second one-way ANOVA followed by the Dunnett's test (bilateral alternative, $P<0.05$ ) was applied to differences among the closed-canopy (reference mean) and both center and edge cores for each gap size.

Pearson's correlation was performed to examine the relationships within physicochemical or biological variables and the gap size, this latter simply scaled in three increasing levels. Significant levels were accepted at $\mathrm{P}<0.05$ and $\mathrm{P}<0.01$. All the analyses were performed with the software SPSS $^{\circledast}$ version 20.0 (IBM, Armonk, NY, USA).

\section{Results}

Soil physico-chemical characteristics

Forest gaps significantly affected some properties of the soil (Tab. 1). For the physical characteristics, gap size affected the clay $(P=0.011-$ Tab. 1$)$ and sand $(P=0.018$ - Tab. 1) proportion, with the medium size showing the lowest values for sand and the highest for clay (Tab. 2). Moreover, independently form the gap size, the sand percentage was significantly lower in the center than the gap-edge (position effect, $\mathrm{P}=$ 0.022 - Tab. 1) the opposite for the clay (position effect, $P=0.044-$ Tab. 1). The gap size affected the bulk density as well $(P=0.008-$ Tab. 1), increasing from the smaller to the larger size (Tab. 2). For the chemical properties, no significant differences occurred between the different gap sizes, whereas a significant gradient (with-

Tab. 2 - Physico-chemical variables for two within-gap position and three gap-size classes, and the adjacent closed canopy. Values are the mean ( \pm standard deviation) of 5 replicates, 15 replicates for the closed-canopy only. The letters a, b, and $c$ indicate signifi cant differences between all positions (LSD, $P<0.05)$; the letters $x$ and $y$ indicate significant differences between within-gap positions and closed canopy (Dunnet's test, bilateral alternative, $P<0.05)(\mathrm{SOC})$ : Soil organic carbon; (Total N): Total Nitrogen; $(P)$ : Phosphorus; (BD): Bulk density.

\begin{tabular}{|c|c|c|c|c|c|c|c|}
\hline \multirow{2}{*}{ Variable } & \multicolumn{2}{|l|}{ Small } & \multicolumn{2}{|l|}{ Medium } & \multicolumn{2}{|l|}{ Large } & \multirow{2}{*}{$\begin{array}{l}\text { Closed } \\
\text { canopy }\end{array}$} \\
\hline & gap-center & gap-edge & gap-center & gap-edge & gap-center & gap-edge & \\
\hline SOC (\%) & $5.32 \pm 1.47$ & $6.41 \pm 1.56^{b}$ & $3.86 \pm 1.42^{\mathrm{ax}}$ & $5.52 \pm 0.48^{b}$ & $4.81 \pm 0.97$ & $5.74 \pm 2.06^{b}$ & $5.98 \pm 1.36^{y}$ \\
\hline Total N (\%) & $0.45 \pm 0.13$ & $0.55 \pm 0.12^{b}$ & $0.33 \pm 0.12^{a x}$ & $0.47 \pm 0.04$ & $0.43 \pm 0.08$ & $0.49 \pm 0.18^{b}$ & $0.51 \pm 0.12^{y}$ \\
\hline$P\left(\mathrm{mg} \mathrm{kg}^{-1}\right)$ & $5.76 \pm 1.95$ & $4.92 \pm 0.67$ & $4.95 \pm 2.72$ & $4.24 \pm 0.47$ & $6.00 \pm 2.96$ & $6.68 \pm 1.85$ & $5.34 \pm 2.54$ \\
\hline Clay (\%) & $20.90 \pm 4.92$ & $15.50 \pm 3.48^{a}$ & $25.10 \pm 3.09^{b}$ & $22.80 \pm 3.57^{b}$ & $19.10 \pm 8.08$ & $15.40 \pm 4.57^{\mathrm{a}}$ & $19.90 \pm 5.83$ \\
\hline Silt (\%) & $10.50 \pm 1.37$ & $11.10 \pm 2.99^{a}$ & $7.55 \pm 2.08^{b}$ & $8.80 \pm 3.61$ & $9.92 \pm 3.22$ & $9.80 \pm 1.16$ & $10.20 \pm 3.34$ \\
\hline Sand (\%) & $68.50 \pm 3.64^{b}$ & $73.30 \pm 1.91^{a}$ & $67.30 \pm 2.12^{b}$ & $68.40 \pm 2.77^{b}$ & $70.90 \pm 5.27$ & $74.80 \pm 4.70^{a}$ & $69.70 \pm 4.38$ \\
\hline $\mathrm{pH}$ & $6.83 \pm 0.21$ & $6.72 \pm 0.40$ & $7.09 \pm 0.27^{a}$ & $6.72 \pm 0.23^{b}$ & $6.85 \pm 0.26$ & $6.76 \pm 0.21$ & $6.87 \pm 0.27$ \\
\hline $\mathrm{BD}\left(\mathrm{g} \mathrm{m}^{-3}\right)$ & $1.28 \pm 0.17^{b}$ & $1.27 \pm 0.20^{b}$ & $1.53 \pm 0.12$ & $1.29 \pm 0.23^{b}$ & $1.69 \pm 0.32^{a x}$ & $1.54 \pm 0.23$ & $1.33 \pm 0.18^{y}$ \\
\hline Moisture (\%) & $43.70 \pm 9.95$ & $38.60 \pm 9.39$ & $32.80 \pm 6.98$ & $43.20 \pm 4.93$ & $41.40 \pm 13.4$ & $38.30 \pm 4.02$ & $34.90 \pm 5.90$ \\
\hline
\end{tabular}


Tab. 3 - F and P values of ANOVA (GLM) for the effects of gap-size and within gap core position for gaps cores only on soil biological variables. (MBC): Microbial Biomass Carbon; (MBP): Microbial Biomass Phosphorus; (MBN): Microbial Biomass Nitrogen.

\begin{tabular}{|c|c|c|c|c|}
\hline \multirow[t]{2}{*}{ Variable } & \multirow[t]{2}{*}{ Stats } & Gap size & $\begin{array}{l}\text { Within Gap } \\
\text { Position }\end{array}$ & $\begin{array}{c}\text { Gap size } \times \\
\text { W-G Position }\end{array}$ \\
\hline & & $(d f=2)$ & $(d f=1)$ & $(d f=2)$ \\
\hline \multirow[t]{2}{*}{$M B C\left(\mathrm{mg} \mathrm{kg}^{-1}\right)$} & $\mathrm{F}$ & 0.091 & 0.968 & 0.574 \\
\hline & $P$ & 0.914 & 0.335 & 0.571 \\
\hline \multirow[t]{2}{*}{ MBP $\left(\mathrm{mg} \mathrm{kg}^{-1}\right)$} & $\mathrm{F}$ & 0.176 & 3.853 & 0.912 \\
\hline & $P$ & 0.839 & 0.061 & 0.415 \\
\hline \multirow[t]{2}{*}{ MBN $\left(\mathrm{mg} \mathrm{kg}^{-1}\right)$} & $\mathrm{F}$ & 1.802 & 1.226 & 1.301 \\
\hline & $P$ & 0.189 & 0.281 & 0.292 \\
\hline \multirow[t]{2}{*}{$\mathrm{MBC} / \mathrm{MBN}$} & $\mathrm{F}$ & 2.364 & 0.341 & 0.583 \\
\hline & $P$ & 0.121 & 0.566 & 0.567 \\
\hline \multirow[t]{2}{*}{$M B C / M B P$} & $\mathrm{~F}$ & 0.241 & 2.008 & 0.474 \\
\hline & $P$ & 0.787 & 0.169 & 0.628 \\
\hline \multirow[t]{2}{*}{$M B N / M B P$} & $\mathrm{~F}$ & 1.012 & 0.418 & 0.858 \\
\hline & $P$ & 0.379 & 0.524 & 0.436 \\
\hline \multirow[t]{2}{*}{$\mathrm{MBC} / \mathrm{SOC} \%$} & $\mathrm{~F}$ & 0.366 & 0.235 & 0.067 \\
\hline & $P$ & 0.698 & 0.633 & 0.935 \\
\hline \multirow[t]{2}{*}{ MBN/Total N } & $\mathrm{F}$ & 2.116 & 0.29 & 2.749 \\
\hline & $P$ & 0.146 & 0.596 & 0.087 \\
\hline \multirow[t]{2}{*}{$M B P / P$} & $\mathrm{~F}$ & 0.045 & 2.436 & 1.164 \\
\hline & $P$ & 0.956 & 0.134 & 0.333 \\
\hline \multirow{2}{*}{$\begin{array}{l}\text { Respiration } \\
\left(\mathrm{mg} \mathrm{CO}_{2}-\mathrm{C} \mathrm{g}^{-1} \text { soil d } \mathrm{d}^{-1}\right)\end{array}$} & $\mathrm{F}$ & 0.847 & 0.201 & 1.118 \\
\hline & $P$ & 0.441 & 0.658 & 0.343 \\
\hline
\end{tabular}

in-gap-position effect) was observed for SOC $(P=0.034)$, total $N(P=0.028)$ and the $\mathrm{pH}(\mathrm{P}=0.048)$ with the SOC and total $\mathrm{N}$ increasing from the center to the edge, the opposite for the $\mathrm{pH}$.

The closed-canopy did not show any significant difference with gaps for all properties, with the only exception of the lower SOC and total $\mathrm{N}$ concentrations for the medium sized and the higher BD for the large sized gaps, both measured at the center of the gap. Correlation highlighted the relationship among those variables affected by within-gap-position effect. Moreover, gap size correlated positively only with BD (Tab. S1 in Supplementary material).

\section{Soil microbial biomass $C, N$ and $P$}

As shown in Tab. 3, forest gaps had no influence on the biological properties of the soil $(P>0.05)$. MBP marginally missed the significance for the variance of within gap position $(P=0.061-$ Tab. 3$)$ with values at the center always lower than at the edge, significant only for the medium sized gap (Tab. 4); MBN/total $\mathrm{N}$ marginally missed the significance for the gap size $\times$ within gap position interaction $(P=0.087)$ with values at the gap center higher than those at the edge except for the medium sized gap. No differences occurred also between the three controls, so that they were pooled and treated as one. Although not significantly, there was a general trend for the gaps to have MBC, MBP, MBN concentrations and their ratios higher than the closed-canopy plots. MBC directly correlated with $M B P$ and its own ratio to MBN and SOC. In the microbial biomass, the C:N ratio increased with decreasing $\mathrm{N}: \mathrm{P}$ and $\mathrm{N}$ :total $\mathrm{N}$ ratios (Tab. S1, Supplementary material). Between physico-chemical and biological variables, it is worth to note the direct relationship between $M B C$ and silt percentage. Nitrogen in microbial biomass (MBN) increased with increasing $\mathrm{N}$ and SOC concentrations into the soil, whereas an inverse relationship did occur with soil $\mathrm{pH}$ and BD (Tab. S1).

\section{Discussion}

This work highlighted that changes in the size of gap six years after logging may affects soil physico-chemical characteristics rather than the microbial biomass and soil respiration. This outcome is particularly evident for the medium-sized gaps in this study $\left(131-175 \mathrm{~m}^{2}\right)$. Moreover, some of the soil chemical characteristics such as SOC and total $\mathrm{N}$ showed a significant decrease in the center of gaps, independently from their size. Studies on the correlation between canopy gap size and BD have provided inconsistent results; correlation was found positive in broad-leaved Pinus koraiensis forests (Zhang \& Zhao 2007) or absent in old-growth Tsuga canadiensis forests (Schliemann \& Bockheim 2014). The lack of correlation of BD with the textural component of the soil made this result hard to fathom, but soil compaction due to the seedling recruitment (Muscolo et al. 2010) cannot be ruled out.

Markedly higher soil moisture levels in the artificial gaps compared to adjacent closed-canopy were found for Danish $\mathrm{Fa}$ gus sylvatica forests (Ritter \& Vesterdal 2006) and Turkish oriental beech, oak, and chestnut stands (Sariyildiz 2008). This can be related to the joint effects of an increased rainfall and reduced transpiration by plant uptake (Latif \& Blackburn 2010, Muscolo et al. 2010).

Tab. 4 - Biological variables for two within-gap position and three gap-size classes, and the adjacent closed canopy. Values are the mean ( \pm standard deviation) of 5 replicates, 15 replicates for the closed-canopy only. The letters a, b, and c indicate significant differences between all positions (LSD, $P<0.05$ ); the letters $x$ and $y$ indicate significant differences between within-gap positions and closed canopy (Dunnet's test, bilateral alternative, $P<0.05)$. (MBC): Microbial Biomass Carbon; (MBP): Microbial Biomass Phosphorus; (MBN): Microbial Biomass Nitrogen; (SOC): Soil Organic Carbon; (Total N): Total Nitrogen; (P): Phosphorus.

\begin{tabular}{|c|c|c|c|c|c|c|c|}
\hline \multirow{2}{*}{ Variable } & \multicolumn{2}{|l|}{ Small } & \multicolumn{2}{|l|}{ Medium } & \multicolumn{2}{|l|}{ Large } & \multirow{2}{*}{$\begin{array}{l}\text { Closed } \\
\text { canopy }\end{array}$} \\
\hline & gap-center & gap-edge & gap-center & gap-edge & gap-center & gap-edge & \\
\hline MBC $\left(\mathrm{mg} \mathrm{kg}^{-1}\right)$ & $405.60 \pm 256.1$ & $371.70 \pm 169.6$ & $294.50 \pm 138.8$ & $463.70 \pm 271.8$ & $370.30 \pm 180.4$ & $466.40 \pm 237.6$ & $295.50 \pm 191.4$ \\
\hline $\operatorname{MBP}\left(\mathrm{mg} \mathrm{kg}^{-1}\right)$ & $5.20 \pm 3.18$ & $5.63 \pm 2.33$ & $3.87 \pm 1.80^{a}$ & $8.85 \pm 4.47^{b}$ & $5.21 \pm 2.08$ & $7.74 \pm 5.47$ & $1.94 \pm 0.61$ \\
\hline MBN $\left(\mathrm{mg} \mathrm{kg}^{-1}\right)$ & $102.90 \pm 47.0$ & $106.40 \pm 81.9$ & $51.70 \pm 24.8$ & $116.30 \pm 39.1$ & $63.20 \pm 47.2$ & $58.50 \pm 38.4$ & $83.90 \pm 55.9$ \\
\hline$M B C / M B N$ & $2.87 \pm 1.70$ & $1.94 \pm 0.98$ & $6.69 \pm 4.07$ & $4.82 \pm 4.84$ & $4.71 \pm 2.74$ & $6.03 \pm 4.16$ & $1.80 \pm 0.80$ \\
\hline $\mathrm{MBC} / \mathrm{MBP}$ & $110.70 \pm 74.2$ & $66.48 \pm 21.6$ & $90.30 \pm 57.6$ & $54.90 \pm 25.5$ & $83.60 \pm 66.2$ & $82.30 \pm 44.7$ & $77.70 \pm 51.9$ \\
\hline MBN/MBP & $44.10 \pm 40.2$ & $21.50 \pm 20.2$ & $18.60 \pm 17.9$ & $23.60 \pm 21.5$ & $17.70 \pm 21.2$ & $17.60 \pm 22.1$ & $26.30 \pm 28.8$ \\
\hline $\mathrm{MBC} / \mathrm{SOC}$ & $72.30 \pm 33.9$ & $65.90 \pm 37.8$ & $79.80 \pm 42.0$ & $67.00 \pm 40.3$ & $59.80 \pm 24.7$ & $59.20 \pm 27.4$ & $49.40 \pm 32.4$ \\
\hline MBN/Total N & $260.90 \pm 138.1^{a}$ & $135.10 \pm 107.8$ & $151.70 \pm 44.3$ & $239.70 \pm 67.6$ & $130.20 \pm 105.4$ & $109.50 \pm 81.22^{b}$ & $168.90 \pm 105.8$ \\
\hline$M B P / P$ & $0.90 \pm 0.43$ & $1.13 \pm 0.36$ & $0.63 \pm 0.36$ & $1.39 \pm 0.38$ & $0.96 \pm 0.48$ & $0.93 \pm 0.89$ & $0.93 \pm 0.61$ \\
\hline $\begin{array}{l}\text { Respiration (mg } \\
\left.\mathrm{CO}_{2}-\mathrm{C} \mathrm{g}^{-1} \text { soil d } \mathrm{d}^{-1}\right)\end{array}$ & $0.10 \pm 0.06$ & $0.10 \pm 0.04$ & $0.09 \pm 0.05$ & $0.13 \pm 0.03$ & $0.14 \pm 0.03$ & $0.11 \pm 0.04$ & $0.09 \pm 0.05$ \\
\hline
\end{tabular}


The openness of the canopy induced a significant decrease of soil $\mathrm{pH}$ at the edge of the gap, independently from its size, but no difference occurred in comparison to the closed canopy. Zhang \& Zhao (2007) found no significant difference for soil $\mathrm{pH}$ between canopy gaps and closed-canopy sites in broad-leaved Pinus koraiensis forests. Kooch et al. (2010) reported a higher amount of $\mathrm{pH}$ for the large gaps in comparison to the medium gaps. Interestingly, the inverse pattern occurred for $\mathrm{SOC}$ and total $\mathrm{N}$, resulting in a significative negative correlation with soil $\mathrm{pH}$. Many factors could affect soil $\mathrm{pH}$, such as salt base saturation, soil redox state, soil water content, and $\mathrm{CO}_{2}$ partial pressure in soils. The increase of soil respiration with the gap opening, though not observed in this study with the only exception for the large gaps, increases $\mathrm{HCO}_{3}{ }^{2-}$ concentration resulting in higher pH (Pujia et al. 2014).

These findings are partially compatible with those of Ritter \& Bjørnlund (2005) who indicated that gap had no influence on the amount of organic material of the soil in Fagus sylvatica stands. In fact, in this study the canopy openness affected anyhow the amount of SOC and $\mathrm{N}$ available into the soil in the central area of the gap, particularly for the medium size gaps. The lack of significance for the smaller and larger gaps might be related to the small number of soil samples in comparison to the high soil heterogeneity. The lack of noticeable changes among gaps in this study could be also attributed to resistance of forests to small scale disturbances (Ritter \& Bjørnlund 2005).

Regarding the soil biological variables, the slight changes observed among gaps, although not statistically significant, may be attributed to vegetation type (Ravindran \& Yang 2015), changes in the microclimatic properties of the soil (Bolat 2014), and gaps age. Microbial biomass changes according to soil temperature, moisture, and depth of soil (Ravindran \& Yang 2015). In addition to microclimate conditions, variations of soil biological characteristics may also be related to soil compaction and reduction in woody residuals (Lewandowski et al. 2015). In fact, discrepancy in the quantity and quality of leaf and root litters can be an essential factor affecting the microbial biomass of the soil (Yang et al. 2010). The significant direct correlations observed between nitrogen concentration in microbial biomass (MBN) and $\mathrm{N}$ and $\mathrm{SOC}$ concentrations into the soil highlighted this essential factor, though independent form the size of gaps. In this study, microbial biomass markedly increased from closed-canopy to gaps (Tab. 4). Micro-environmental conditions that benefit microbial activity, including temperature of air and soil, solar radiation and soil moisture, have been found more favorable in gaps than in adjacent closed-canopy stands, so that gaps could have higher rates of decomposition than the closed forest (Schlie- mann \& Bockheim 2014, Adachi et al. 2006). Although soil respiration is a valuable indicator to study decomposition status, it is variable in nature and changes in response to moisture, available resources, and temperature (Bolat 2014). In this study, soil microbial biomass in terms of $M B C$, $M B N, M B P$ and their ratios were higher in gaps than in closed canopy highlighting the higher nutrient concentrations in the gaps, though their values were lower at the center than at the edge. Moreover, the ratio of $M B C$ to soil organic matter (MBC/SOC) is used to compare the quality of soil with different organic material concentrations (Chandra et al. 2016). The higher MBC/SOC ratios observed in gaps and in particular at the center highlighted the higher availability of organic matter provided by the litter of herb-tree layer plants in this position. Likewise, MBN/total N and MBP/available $\mathrm{P}$ indicate the availability of $\mathrm{N}$ and $\mathrm{P}$. A decrease in MBN with increasing gap size (Tab. 4) might be related to the influence of soil temperature and moisture on decreasing microbial biomass and decomposition of organic matter (Muscolo et al. 2010). According to our results, correlations observed between some of the physico-chemical and biological investigated variables highlighted the occurrence of a gradient from the edge to the center of the gap responsive to the openness of the canopy, and such gradient is independent from the size of gap.

\section{Conclusions}

This research examined the influence of artificial gaps created under single- tree selection in oriental beech stand on some soil properties and its comparison with undisturbed adjacent stands. According to results, it can be concluded that there are relative similar conditions in terms of many soil properties among gaps and adjacent closed-canopy stands six years after logging, though canopy openness triggered a reduction in carbon and nitrogen availability at the center of the gaps, independently from their size. Therefore, if aimed at preserving an uneven aged structure along with soil quality in temperate broadleaved deciduous forest as the oriental beech stands in the Hyrcanian region, single-tree selection practice for harvesting trees can be recommended as sustainable forest management type.

\section{Acknowledgements}

We would like to express our gratitude to Lorestan University, Lorestan, Iran to provide us with financial supports.

\section{References}

Adachi M, Bekku YS, Rashidah W, Okuda T, Koizumi H (2006). Differences in soil respiration between different tropical ecosystems. Applied Soil Ecology 34: 2-3.), 258-265. - doi: 10.1016/j.apsoil.2006.01.006

Alef K, Nannipieri P (1995). Methods in applied soil microbiology and biochemistry. Academic
Press, London, UK, pp. 576.

Al-Shammary AAG, Kouzani AZ, Kaynak A, Khoo SY, Norton M, Gates W (2018). Soil bulk density estimation methods: a review. Pedosphere 28 (4): 581-596. - doi: 10.1016/S1002-016o(18)600 34-7

Arunachalam A, Arunachalam K (2000). Influence of gap size and soil properties on microbial biomass in a subtropical humid forest of north-east India. Plant and Soil 223 (1-2): 187195. - doi: 10.1023/A:1004828221756

Bolat I (2014). The effect of thinning on microbial biomass $\mathrm{C}, \mathrm{N}$ and basal respiration in black pine forest soils in Mudurnu, Turkey. European Journal of Forest Research 133 (1): 131-139. - doi: 10.1007/s10342-013-0752-8

Bouyoucos GJ (1962). Hydrometer method improved for making particle size analysis of soils. Agronomy Journal 54 (5): 464-465. - doi: 10.213 4/agronj1962.00021962005400050028x

Brookes PC, Powlson DS, Jenkinson DS (1982). Measurement of microbial biomass phosphorus in soil. Soil Biology and Biochemistry 14 (4): 319-329. - doi: 10.1016/0038-0717(82)90001-3

Brookes PC, Landman A, Pruden G, Jenkinson DS (1985). Chloroform fumigation and the release of soil nitrogen: a rapid direct extraction method to measure microbial biomass nitrogen in soil. Soil biology and biochemistry 17 (6): 837842. - doi: 10.1016/0038-0717(85)90144-0

Chandra LR, Gupta S, Pande V, Singh N (2016). Impact of forest vegetation on soil characteristics: a correlation between soil biological and physico-chemical properties. 3 Biotech 6 (2): 188. - doi: 10.1007/s13205-016-0510-y

Chaouqi N, El Gharous M, Naceri Bouzziri Z M (2017). A simplified method for laboratory soil analysis. International Journal of Geomate 12 (34): 76-81. - doi: 10.21660/2017.34.2706

D'Oliveira MV, Ribas LA (2011). Forest regeneration in artificial gaps twelve years after canopy opening in Acre State Western Amazon. Forest Ecology and Management 261 (11): 1722-1731. doi: 10.1016/j.foreco.2011.01.020

Joergensen RG, Mueller T (1996). The fumigation-extraction method to estimate soil microbial biomass: calibration of the kEN value. Soil Biology and Biochemistry 28 (1): 33-37. - doi: 10.1016/0038-0717

He Z, Liu J, Wu C, Zheng S, Su S, Wu C (2012). Effects of forest gaps on some microclimate variables in Castanopsis kawakamii natural forest. Journal of Mountain Science 9 (5): 706-714. doi: 10.1007/s11629-012-2304-y

Kooch Y, Hosseini SM, Mohammadi J, Hojjati SM (2010). The effects of gap disturbance on soil chemical and biochemical properties in a mixed beech-hornbeam forest of Iran. Ecologia Balkanica 2: 39-56.

Latif ZA, Blackburn GA (2010). The effects of gap size on some microclimate variables during late summer and autumn in a temperate broadleaved deciduous forest. International Journal of Biometeorology 54 (2): 119-129. - doi: 10.1007/ s00484-009-0260-1

Lewandowski TE, Forrester JA, Mladenoff DJ, Stoffel JL, Gower ST, Amato D AW, Basler TC (2015). Soil microbial community response and recovery following group selection harvest: temporal patterns from an experimental harvest in a US northern hardwood forest. Forest 
Ecology and Management 340: 82-94. - doi: 10.1016/j.foreco.2014.12.012

Liu Y, Zhang J, Yang W, Wu F, Xu Z, Zhang L, He $X$, Gua L (2018). Canopy gaps accelerate soil organic carbon retention by soil microbial biomass in the organic horizon in a subalpine fir forest. Applied Soil Ecology 125: 169-176. - doi: 10.1016/j.apsoil.2018.01.002

Muscolo A, Sidari M, Mercurio R (2007a). Influence of gap size on organic matter decomposition, microbial biomass and nutrient cycle in Calabrian pine (Pinus laricio Poiret) stands. Forest Ecology and Management 242 (2-3): 412418. - doi: 10.1016/j.foreco.2007.01.058

Muscolo A, Sidari M, Mercurio R (2007b). Variations in soil chemical properties and microbial biomass in artificial gaps in silver fir stands. European Journal of Forest Research 126 (1): 5965. - doi: 10.1007/s10342-006-0145-3

Muscolo A, Sidari M, Bagnato S, Mallamaci C, Mercurio R (2010). Gap size effects on aboveand below-ground processes in a silver fir stand. European Journal of Forest Research 129 (3): 355-365. - doi: 10.1007/s10342-009-0341-z Olsen SR, Cole CV, Watanabe FS, Dean LA (1954). Estimation of available phosphorus in soils by extraction with sodium bicarbonate. USDA Circular 939, US Government Printing Office, Washington, DC, USA, pp. 1-19. [online] URL: http://books.google.com/books?id=d-oaM80x5 agC

Page AL (1992). Methods of soil analysis. ASA and SSSA Publishers, Madison, WI, USA, pp. 321.

Pang X, Bao W, Zhu B, Cheng W (2013). Responses of soil respiration and its temperature sensitivity to thinning in a pine plantation. Agricultural and Forest Meteorology 171: 57-64. doi: 10.1016/j.agrformet.2012.12.001

Papuga K, Kaszubkiewicz J, Wilczewski W, Stas M, Belowski J, Kawalko D (2018). Soil grain size analysis by the dynamometer method-a comparison to the pipette and hydrometer method. Soil Science Annual 69 (1): 17-27. - doi: 10.2478/ssa-2018-0003

Pujia Y, Qiang L, Hongtao J, Guangdi L, Wei Z, Xiangiin S, Baba D (2014). Effect of cultivation on dynamics of organic and inorganic carbon stock in Songnen plain. Agronomy Journal 106 (5): 1574-1582. - doi: 10.2134/agronj14.0113

Ravindran A, Yang SS (2015). Effects of vegetation type on microbial biomass carbon and nitrogen in subalpine mountain forest soils. Journal of Microbiology, Immunology and Infection 48 (4): 362-369. - doi: 10.1016/j.jmii.2014.02.003

Ritter E, Bjørnlund L (2005). Nitrogen availability and nematode populations in soil and litter after gap formation in a semi-natural beech-dominated forest. Applied Soil Ecology 28 (2): 175189. - doi: 10.1016/j.apsoil.2004.07.002

Ritter E, Vesterdal L (2006). Gap formation in Danish beech (Fagus sylvatica) forests of low management intensity: soil moisture and nitrate in soil solution. European Journal of Forest Research 125 (2): 139-150. - doi: 10.1007/s103 42-005-0077-3

Saner P, Lim R, Burla B, Ong RC, Schrer-Lorenzen $M$, Hector A (2009). Reduced soil respiration in gaps in logged lowland dipterocarp forests. Forest Ecology and Management 258 (9): 20072012. - doi: 10.1016/j.foreco.2009.07.048

Sariyildiz T (2008). Effects of gap-size classes on long-term litter decomposition rates of beech, oak and chestnut species at high elevations in Northeast Turkey. Ecosystems 11 (6): 841-853. doi: 10.1007/s10021-008-9164-X

Scharenbroch BC, Bockheim JG (2007). Impacts of forest gaps on soil properties and processes in old growth northern hardwood-hemlock forests. Plant and Soil 294 (1-2): 219-233. - doi: 10.10 07/s11104-007-9248-y

Schliemann SA, Bockheim JG (2014). Influence of gap size on carbon and nitrogen biogeochemical cycling in Northern hardwood forests of the Upper Peninsula, Michigan. Plant and Soil 377 (1-2): 323-335. - doi: 10.1007/s11104-013-2005-5 Vance ED, Brookes PC, Jenkinson DS (1987). An extraction method for measuring soil microbial biomass $C$. Soil biology and biochemistry 19 (6): 703-707. - doi: 10.1016/0038-0717(87)90052-6 Walkley A, Black IA (1934). Estimation of soil organic carbon by the chromic acid titration method. Soil Science 37: 29-38. - doi: 10.1097/ 00010694-193401000-00003

Yamamoto SI (2000). Forest gap dynamics and tree regeneration. Journal of Forest Research 5 (4): 223-229. - doi: 10.1007/BF02767114

Yang K, Zhu J, Zhang M, Yan Q, Sun OJ (2010). Soil microbial biomass carbon and nitrogen in forest ecosystems of Northeast China: a comparison between natural secondary forest and larch plantation. Journal of Plant Ecology 3 (3): 175-182. - doi: 10.1093/jpe/rtq022

Yang Y, Geng Y, Zhou H, Zhao G, Wang L (2017). Effects of gaps in the forest canopy on soil microbial communities and enzyme activity in a Chinese pine forest. Pedobiologia 61: 51-60. doi: 10.1016/j.pedobi.2017.03.001

Zhang C, Zhao X (2007). Soil properties in forest gaps and under canopy in broad-leaved Pinus koraiensis forests in Changbai Mountainous region, China. Frontiers of Forestry in China 2 (1): 60-65. - doi: 10.1007/s11461-007-0009-0

\section{Supplementary Material}

Tab. S1 - Pearson's correlation between gap size, soil physico-chemical and biological variables.

Link: Amolikondori_3205@supplo01.pdf 